\title{
Hydrogen peroxide contributes to the ultraviolet-B (280-315 nm) induced oxidative stress of plant leaves through multiple pathways
}

\author{
Gyula Czégény ${ }^{1,2}$, Min Wu ${ }^{3}$, András Dér ${ }^{4}$, Leif A. Eriksson ${ }^{3}$, Åke Strid ${ }^{5}$, and Éva Hideg ${ }^{1, *}$ \\ ${ }^{1}$ Institute of Biology, University of Pécs, Pécs, Hungary \\ ${ }^{2}$ Institute of Plant Biology, Biological Research Centre, Szeged, Hungary \\ ${ }^{3}$ Department of Chemistry and Molecular Biology, University of Gothenburg, Göteborg, Sweden \\ ${ }^{4}$ Institute of Biophysics, Biological Research Centre, Szeged, Hungary \\ ${ }^{5}$ Örebro Life Science Centre, School of Science \& Technology, Örebro University, Örebro, Sweden \\ "To whom correspondence should be addressed: Éva Hideg, Institute of Biology, University of Pécs, \\ Ifjúság útja 6. H-7624 Pécs, Hungary, Tel.: +3672 503600; Fax: +3672 503634; Email: \\ ehideg@gamma.ttk.pte.hu
}

Keywords: Arabidopsis; computer modelling; hydrogen peroxide; hydroxyl radical; leaf; oxygen radicals; plant; photosynthesis; terephthalic acid; UV photobiology

Abbreviations: DAB, 3,3'-diaminobenzidine; DFT, density functional theory; HTPA, hydroxyterephthalate; PAM, Pulse amplitude modulation; PAR, photosynthetically active radiation 400$700 \mathrm{~nm}$; PSII, Photosystem II; ROS, reactive oxygen species; TD-DFT, time-dependent density functional theory; TPA, terephthalic acid, 1,4-benzenedicarboxylic acid; UV-B, 280-315 nm ultraviolet radiation

\section{Highlights:}

- UV-B can photosensitize hydroxyl radical production from metabolic $\mathrm{H}_{2} \mathrm{O}_{2}$

- $308 \mathrm{~nm}$ UV is more damaging to leaves which have less ${ }^{\circ} \mathrm{OH}$ antioxidant pyridoxine

- UV-B may induce oxidative stress both directly and via ${ }^{\circ} \mathrm{OH}$ from $\mathrm{H}_{2} \mathrm{O}_{2}$ photolysis

\begin{abstract}
Solar UV-B (280-315 $\mathrm{nm})$ radiation is a developmental signal in plants but may also cause oxidative stress when combined with other environmental factors. Using computer modelling and in solution experiments we show that UV-B is capable of photosensitizing hydroxyl radical production from hydrogen peroxide. We present evidence that the oxidative effect of UV-B in leaves is at least two-fold: (i) it increases cellular hydrogen peroxide concentrations, to a larger extent in pyridoxine antioxidant mutant pdx1.3-1 Arabidopsis and (ii) is capable of a partial photo-conversion of both 'natural' and 'extra' hydrogen peroxide to hydroxyl radicals. As stress conditions other than UV can increase cellular hydrogen peroxide levels, synergistic deleterious effects of various stresses may be expected already under ambient solar UV-B.
\end{abstract}




\section{Introduction}

UV-B (280-315 $\mathrm{nm})$ radiation is the highest energy component of sunlight reaching the Earth's surface. While prolonged exposure to solar UV-B can be harmful for humans [1], plants grown outdoors have multiple lines of adaptive mechanisms to minimize oxidative damage [2]. Results of the past decade of plant research suggest that solar UV-B is rather a developmental factor than a stressor [3,4]. Nevertheless, laboratory experiments with above ambient UV-B doses showed that this radiation is capable of impairing photosynthesis and causing oxidative stress [5,6]. Production of a variety of reactive oxygen species (ROS) was demonstrated in photosynthetic organism in response to high UV-B doses [7-12]. In controlled environment UV experiments, plants are typically first grown indoors in the absence of UV and then only mature leaves are exposed to supplementary UV. Such an experiment, using UV-B tubes giving 170-180\% of ambient doses, resulted in increased $\mathrm{H}_{2} \mathrm{O}_{2}$ concentrations in tobacco leaves [11]. Lower, near ambient UV doses resulted in higher peroxidase activity [12], but so far there has been no direct evidence for ROS occurrence in plants grown under natural sunlight.

Hydrogen peroxide is of special importance among the ROS since it is potentially involved in responses to abiotic stress conditions as a signalling component. Physiologically, the significance of $\mathrm{H}_{2} \mathrm{O}_{2}$ as a direct cell-to-cell messenger [13] is either facilitated by aquaporins [14] or by direct diffusion across membranes [15]. Photosynthetically active radiation (PAR, 400-700 nm), corresponding to the visible part of the solar spectrum, leads to $\mathrm{H}_{2} \mathrm{O}_{2}$ production in chloroplasts by photosystem I [16] and probably also by photosystem II [17]. $\mathrm{H}_{2} \mathrm{O}_{2}$ is also a product of mitochondrial and peroxisomal metabolism or plasma membrane respiratory burst NADPH oxidases [18-19]. It is generally accepted that under high PAR $\mathrm{H}_{2} \mathrm{O}_{2}$ can initiate and probably amplify ROS production for the purpose of signaling [20].

Photobiologically, $\mathrm{H}_{2} \mathrm{O}_{2}$ is of interest because it also absorbs UV wavelengths contained in sunlight. The absorption cross section of $\mathrm{H}_{2} \mathrm{O}_{2}$ increases monotonously as the wavelength decreases from 350 to $190 \mathrm{~nm}$ [21]. In line with this, gas phase $\mathrm{H}_{2} \mathrm{O}_{2}$ has been found to dissociate at wavelengths shorter than ca. $320 \mathrm{~nm}$ [22] with two ground-state hydroxyl radicals being the dominating photolysis products [23]. Experimental studies on aqueous hydrogen peroxide using 'far UV' (253 nm or shorter wavelengths) have revealed that ${ }^{\circ} \mathrm{OH}$ and $\mathrm{HO}_{2}{ }^{\bullet}$ radicals are the major products [24,25]. In a study investigating the effect of UV light on $\mathrm{Fe}^{3+}$ formation from $\mathrm{Fe}^{2+}$ in the presence of chelator complexes, the obtained action spectrum of iron-mediated Fenton reaction revealed a monotonous decrease in ${ }^{\circ} \mathrm{OH}$ production when going from shorter to longer wavelengths in the $250 \mathrm{~nm}$ to $450 \mathrm{~nm}$ range [26]. UV flash photolysis experiments have also been carried out on hydrogen peroxide molecules embedded in a solid argon matrix [27]. In this case, the 193-nm photolysis of $\mathrm{H}_{2} \mathrm{O}_{2}$ produced a van der Waals complex between water and a ground-state oxygen atom, $\mathrm{H}_{2} \mathrm{O} \cdots \mathrm{O}(3 \mathrm{P})$, and free ${ }^{\circ} \mathrm{OH}$ radicals. The kinetic model of the photolysis of $\mathrm{H}_{2} \mathrm{O}_{2}$ in solid argon could be described as follows: 


$$
\mathrm{H}_{2} \mathrm{O} \cdots \mathrm{O} \leftrightarrow \mathrm{H}_{2} \mathrm{O}_{2} \rightarrow 2^{\bullet} \mathrm{OH}
$$

While the yield of $\mathrm{H}_{2} \mathrm{O} \cdots \mathrm{O}$ was found to decrease with increasing wavelengths between $193 \mathrm{~nm}$ and $320 \mathrm{~nm}$, a light-induced recovery of hydrogen peroxide from the water-oxygen complex was observed upon a secondary excitation around $300 \mathrm{~nm}$ [28]. Such a reaction scheme may give a hint on the interpretation of light-induced reactions of $\mathrm{H}_{2} \mathrm{O}_{2}$ molecules under strict steric constraints, e.g. when present in biological matrices, such as in plant tissue.

In this paper we report on the possible roles of $\mathrm{H}_{2} \mathrm{O}_{2}$ in plants in response to UV-B irradiation. We present evidence for UV-B-induced enhancement of $\mathrm{H}_{2} \mathrm{O}_{2}$ production, and $\mathrm{UV}$-B-induced conversion of both 'natural' and 'extra' $\mathrm{H}_{2} \mathrm{O}_{2}$ to ${ }^{\circ} \mathrm{OH}$.

\section{Materials and Methods}

\section{Hydroxyl radical detection in aqueous solutions}

To determine the action spectrum of ${ }^{\circ} \mathrm{OH}$ production from $10 \mu \mathrm{M} \mathrm{H}_{2} \mathrm{O}_{2}$ in $50 \mathrm{mM}$ Naphosphate buffer ( $\mathrm{pH} 7.0$ ), the solution was irradiated with monochromatic UV (half bandwidth 0.4 $\mathrm{nm}$ ) from an Opolette 355II+UV tuneable laser (Opotek Inc., Carlsbad, CA) in the presence of 250 $\mu \mathrm{M}$ terephthalic acid (TPA, 1,4-benzenedicarboxylic acid). Hydroxyl radical production was assessed on the basis of its ability to oxidize TPA into 2-hydroxyterephthalate (HTPA), which is accompanied by a marked increase in 315/420 nm fluorescence [9]. HTPA fluorescence was measured using a Cary Eclipse spectrofluorometer (Agilent Technologies, Santa Clara, CA) after exposing the solution to UV-B radiation. These experiments were performed three times for each wavelength, using fresh reaction mixtures and one the following energies: 50, 100 and 200 mJ. HTPA fluorescence increased linearly with the UV-B energy and a slope was determined for each wavelength. An action spectrum was constructed by repeating the experiment at 280, 284, 288, 290, 292, 294, 296, 298, 300, 304, 308, $312,316 \mathrm{~nm}$ and plotting calculated slopes versus wavelengths. In this plot $1-\mathrm{R}^{2}$ values of (where $\mathrm{R}^{2}$ is the coefficient of determination) of a these linear fits were used as error bars. The experimental action spectrum was fitted with the sum of two Gaussian components using the above $\mathrm{R}^{2}$ values as weighting factors for each wavelength-slope parameter pair. Least squares fits were performed using SigmaPlot 12 (Systat Software Inc., SanJose, CA, USA) which was also used to make graphs.

\section{Computer modeling}

Along the reaction pathways, all ground state (S0) structures were optimized in vacuum at the hybrid B3LYP Hartree-Fock DFT level of theory, in conjunction with the 6-31+G(d,p) basis set. Harmonic vibrational frequency calculations were performed on the optimized geometries at the same level of theory, to ensure that they correspond to minima on their respective energy surfaces. Product formation was investigated by stretching the specific chemical bonds in steps of $0.05 \AA$ in the ground 
state and at each point re-optimizing the remaining structural parameters. Single-point energy calculations for vertical singlet excitations were calculated at the B3LYP/6-31+G(d,p) level at each point along the dissociation pathways of the $\mathrm{H}_{2} \mathrm{O}_{2}$ molecule and the ${ }^{\circ} \mathrm{OH}$ radical using TD-DFT. The B3LYP formalism is known to generate computed absorption peaks in vacuum that are blue-shifted relative to experiment by $10-15 \mathrm{~nm}$ at $\lambda=250-300 \mathrm{~nm}$ [29-33]. All calculations were performed using the Gaussian 09 package [34].

\section{Plant material and leaf $308 \mathrm{~nm}$ irradiation}

Tobacco (Nicotiana tabacum L. cv. Xanthi) plants were grown in standard soil in growth chambers (Fitoclima D1200, Aralab, Portugal) under long day conditions: $16 \mathrm{~h}$ light $\left(150 \mu \mathrm{mol} \mathrm{m} \mathrm{m}^{-2} \mathrm{~s}^{-1}\right.$ PAR, $\left.25^{\circ} \mathrm{C}\right) / 8 \mathrm{~h}$ dark $\left(20^{\circ} \mathrm{C}\right)$. Arabidopsis thaliana (Col-0 ecotype and pdx1.3-1 mutant [35] plants) were grown in a green-house using a special shading to ensure short day (8/16h) conditions. Daytime PAR was $200-240 \mu \mathrm{mol} \mathrm{m} \mathrm{m}^{-2}$.

$308 \mathrm{~nm}$ monochromatic UV-B radiation $(2 \mathrm{~mJ}, 2.78 \mathrm{~Hz})$ from a Lambda Physik EMG 200, $\mathrm{XeCl}$ excimer laser was applied on a $1 \mathrm{~cm}^{2}$ diameter leaf spot. Tobacco leaves were used to illustrate the effect of local UV-B treatment without detaching these from the plants. For the Arabidopsis experiments, leaves were removed from the plants immediately before UV treatment and $308 \mathrm{~nm}$ was applied for $1 \mathrm{~min}$, then the leaves were either used for visualizing cellular $\mathrm{H}_{2} \mathrm{O}_{2}$ or for photosynthetic electron transport measurements after $30 \mathrm{~min}$ dark adaptation. Arabidopsis leaf experiments were repeated three times using leaves from three different plants grown and treated under identical conditions. The significance of differences between data sets was assessed using unpaired Students t-tests and significantly different datasets $(\mathrm{p}<0.05)$ are labelled with different letters.

\section{Leaf $\mathrm{H}_{2} \mathrm{O}_{2}$ visualization using diamino-benzidine}

Arabidopsis leaves were treated with the $\mathrm{H}_{2} \mathrm{O}_{2}$ probe 3,3'-diaminobenzidine (DAB) immediately after UV irradiation, as described earlier [36]. After a $90 \mathrm{~min}$ incubation in a solution containing $0.75 \mathrm{mg} \mathrm{mL}^{-1} \mathrm{DAB}$, chlorophyll was removed by keeping leaves in $96 \%$ ethanol at $70^{\circ} \mathrm{C}$ ethanol for $4 \mathrm{~h}$ to visualize the characteristic brown staining developed during the reaction between cellular $\mathrm{H}_{2} \mathrm{O}_{2}$ and DAB [37]. After removing chlorophyll, leaves were kept in 1:1 (v:v) water:ethanol for $24 \mathrm{~h}$ before photography. This post-treatment procedure was used in order to avoid possible artefacts arising from the sensitivity of DAB to UV or from the DAB-induced limitation of photosynthesis [36]. In this way, 'snapshots' of actual steady state leaf $\mathrm{H}_{2} \mathrm{O}_{2}$ concentrations were visualized and compared.

\section{Photosynthetic electron transport measurements}

Leaf photosynthetic electron transport can be characterized by photochemical yields and other, non-photochemical pathways. These parameters were calculated from leaf chlorophyll fluorescence yields measured with the MAXI-version of the Imaging-PAM (Heinz Walz GmbH, Effeltrich, Germany). Tobacco leaves were measured by placing whole plants under the detector. Excised Arabidopsis leaves were measured while keeping their petioles wrapped in wet tissue paper to avoid water loss. Before measurements, all leaf samples were first kept in the dark for $30 \mathrm{~min}$. This was 
followed by measurements of $F_{0}$, the minimal fluorescence yield of dark adapted samples, and $F_{m}$, the maximal fluorescence yield measured after a saturating light pulse. Maximum (potential) photochemical quantum yield of photosystem (PS) II was calculated as $F_{v} / F_{m}=\left(F_{m}-F_{0}\right) / F_{m}[38]$.

Division of absorbed PAR into photochemical and non-photochemical processes was characterized in Arabidopsis leaves by also measuring $\mathrm{F}$ and $\mathrm{F}_{\mathrm{m}}{ }^{\prime}$ yields. These were determined after measuring dark adapted $\mathrm{F}_{0}$ and $\mathrm{F}_{\mathrm{m}}$, at the end of a short $(30 \mathrm{sec}$ ) blue actinic light irradiation with 280 $\mu \mathrm{mol} \mathrm{m}{ }^{-2} \mathrm{~s}^{-1}$ PAR. The quantum yields of PSII photochemistry, $\left.\mathrm{Y}(\mathrm{II})=\left(\mathrm{F}_{\mathrm{m}}{ }^{\prime}-\mathrm{F}\right) / \mathrm{F}_{\mathrm{m}}{ }^{\prime}\right)$, non-regulated dissimilative processes, $\mathrm{Y}(\mathrm{NO})=\mathrm{F} / \mathrm{F}_{\mathrm{m}}$, and regulated energy dissipation, $\mathrm{Y}(\mathrm{NPQ})=\mathrm{F} / \mathrm{F}_{\mathrm{m}}{ }^{\prime}-$ $\mathrm{Y}(\mathrm{NO})$, characteristic to each illumination step, were calculated according to Klughammer and Schreiber [39].

Statistics

\section{Results and Discussion}

\section{Experimental action spectrum of the $\mathrm{UV}$-induced $\mathrm{H}_{2} \mathrm{O}_{2} \rightarrow{ }^{\circ} \mathrm{OH}$ reaction}

To investigate whether the high energy UV-B component of sunlight is capable of photosensitizing the decomposition of $\mathrm{H}_{2} \mathrm{O}_{2}$ into ${ }^{\circ} \mathrm{OH}$, experiments were performed using terephthalic acid (TPA) that is converted into the fluorescent hydroxy-terephthalate (HTPA) when reacting with ${ }^{\circ} \mathrm{OH}$. TPA itself has low fluorescence, it is not reactive to $\mathrm{H}_{2} \mathrm{O}_{2}$ [9] and, as shown in Fig.1a, the TPA $\rightarrow$ HTPA conversion is not induced by the applied UV itself. However, when $\mathrm{H}_{2} \mathrm{O}_{2}$ was irradiated with increasing doses of $284 \mathrm{~nm}$ UV-B in the presence of TPA, HTPA fluorescence increased proportionally, demonstrating production of ${ }^{\circ} \mathrm{OH}$ (Fig.1A). This experiment was repeated applying various monochromatic UV wavelengths and the slopes of the dose-dependent increases in the HTPA fluorescence intensity were used for characterizing the ${ }^{\circ} \mathrm{OH}$-generating efficiency. The action spectrum formed by plotting these data against the corresponding wavelengths was maximal between 290 and $300 \mathrm{~nm}$ (Fig.1b), which was very different from the calculated UV absorption spectrum of $\mathrm{H}_{2} \mathrm{O}_{2}$ (Fig.1c) and also from the data of Chu and Anastasio [40] who reported a flat, wavelengthindependent production rate of hydroxyl radicals from frozen $\mathrm{H}_{2} \mathrm{O}_{2}$. Our data suggest the presence of at least two components in the action spectrum and a least squares fit employing two Gaussians, peaking at 296 and $284 \mathrm{~nm}$, gave a satisfactory result (Fig.1B) with $\mathrm{R}^{2}=0.948$.

\section{Calculated $U V$ action spectrum of the $\mathrm{H}_{2} \mathrm{O}_{2} \rightarrow{ }^{\circ} \mathrm{OH}$ reaction}

According to B3LYP/6-31+G(d,p) level calculations (Fig.1C), the computed first absorption wavelength of $\mathrm{H}_{2} \mathrm{O}_{2}$ is located at $268 \mathrm{~nm}$, resulting from the electron transfer from HOMO to LUMO, and at 149, 142 and $124 \mathrm{~nm}$ for the second, third, and fourth absorption wavelengths. Thus, solar UVirradiation is not sufficient to lead to the formation of the excited states that require absorption wavelengths of $<200 \mathrm{~nm}$. A scanning approach was employed to investigate the singlet excited state 
energies along the different pathways, in order to explore the possibility of ${ }^{\circ} \mathrm{OH}$ radical generation by UV-induced $\mathrm{H}_{2} \mathrm{O}_{2}$ dissociation. The $\mathrm{O}-\mathrm{O}$ bond was scanned from $1.48 \AA$ to $2.38 \AA$, with a $0.05 \AA$ step size. For each new point, the structure was re-optimized in the ground state and the vertical singlet excitation energies were calculated. The four lowest singlet excited states were included in the calculations along the reaction coordinate. Singlet state energy curves along the reaction coordinate obtained at the TD-B3LYP/6-31+G(d,p) level showed that the energies for $\mathrm{H}_{2} \mathrm{O}_{2}$ dissociation to ${ }^{\circ} \mathrm{OH}$ are highly endothermic in the ground state and in the third and fourth singlet excited states throughout the scan of the O-O bonds (Suppl. Fig.1A). However, in the first and second excited states, the dissociation of $\mathrm{H}_{2} \mathrm{O}_{2}$ to ${ }^{\circ} \mathrm{OH}$ is spontaneous and a calculated absorption wavelength of approximately 268 $\mathrm{nm}$ (Fig.1C) corresponds to an expected experimental absorption maximum at approx. $280 \mathrm{~nm}$ due to the above-mentioned $10-15 \mathrm{~nm}$ blue-shift of $250-300 \mathrm{~nm}$ absorption wavelengths calculated by the current TD-DFT methodology [29-33].

\section{The main product of $\mathrm{UV}$-induced $\mathrm{H}_{2} \mathrm{O}_{2}$ dissociation is ${ }^{\circ} \mathrm{OH}$}

The UV absorption spectrum of ${ }^{\circ} \mathrm{OH}$ and the action spectrum of ${ }^{\circ} \mathrm{OH}$ dissociation were further investigated to explore whether the ${ }^{\circ} \mathrm{OH}$ generated by UV could dissociate further in the presence of this type of radiation. The computed UV absorption spectrum of ${ }^{\circ} \mathrm{OH}$ (Fig.1D) showed that the longest absorption wavelength is located at $294 \mathrm{~nm}$ (experimentally corresponding to approximately 305 $\mathrm{nm}$ when the above-mentioned blue shift is taken into consideration) with an oscillator strength of 0.0025 , followed by absorptions at 155, 141 and $117 \mathrm{~nm}$ for the second, third and fourth excited states, respectively. Again, natural UV irradiation cannot lead to absorption at the wavelengths shorter than $200 \mathrm{~nm}$. From the calculated action spectrum of ${ }^{\circ} \mathrm{OH}$ dissociation, shown in Fig.1d, the energy barrier is approximately $50 \mathrm{kcal} / \mathrm{mol}$ in the ground state and the first singlet excited state, and the reactions are highly endothermic throughout the scan of the $\mathrm{O}-\mathrm{H}$ bond. It is thus concluded that any further dissociation of ${ }^{\circ} \mathrm{OH}$ generated by UV irradiation will not take place.

The possible formation of ${ }^{\circ} \mathrm{H}$ and ${ }^{\circ} \mathrm{OOH}$ radicals from the $\mathrm{H}_{2} \mathrm{O}_{2}$ molecule in the presence of UV light was also calculated at the TD-B3LYP/6-31+G(d,p) level. The O-H bond was scanned outward from $0.97 \AA$ to $1.87 \AA$, with a step size of $0.05 \AA$. For each new point, the structures were reoptimized in the ground state and the vertical singlet excitation energies calculated. The resulting energy curves of ${ }^{\circ} \mathrm{H}$ and ${ }^{\circ} \mathrm{OOH}$ generation (Suppl. Fig.1B) showed energy barriers of 102.5, 9.6, 28.7, 72.4 , and $68.9 \mathrm{kcal} / \mathrm{mol}$ for the ground state and first, second, third and fourth singlet excited states, respectively. It is concluded that the formation of ${ }^{\circ} \mathrm{H}$ and ${ }^{\circ} \mathrm{OOH}$ from $\mathrm{UV}$-induced dissociation of the $\mathrm{H}_{2} \mathrm{O}_{2}$ molecule is not spontaneous, albeit the $\mathrm{S} 1$ state does provide a slight possibility for the reaction. However, compared to the spontaneous dissociation of $\mathrm{H}_{2} \mathrm{O}_{2}$ into ${ }^{\circ} \mathrm{OH}$, the formation of ${ }^{\circ} \mathrm{H}$ and ${ }^{\circ} \mathrm{OOH}$ is expected to be essentially nonexistent.

\section{The possibility and consequences of an $\mathrm{UV}$ photosensitized $\mathrm{H}_{2} \mathrm{O}_{2} \rightarrow{ }^{\circ} \mathrm{OH}$ reaction in leaves}


The above calculations and model studies in solution show that UV-B can potentially photosensitize the $\mathrm{H}_{2} \mathrm{O}_{2} \rightarrow{ }^{\circ} \mathrm{OH}$ reaction in vivo. Such reactions could be realized and biologically relevant if (i) leaves contain sufficient amounts of $\mathrm{H}_{2} \mathrm{O}_{2}$ as substrate, (ii) UV-B penetrates $\mathrm{H}_{2} \mathrm{O}_{2}$-containing tissues, and (iii) cellular antioxidants are not capable of neutralizing all ROS at their production site to prevent cellular damage. In the following we show that the above conditions are applicable to leaves exposed to $308 \mathrm{~nm}$ UV-B in the laboratory and hypothesize that the UV-B component of sunlight is capable of bringing about similar reactions.

The most stable ROS, $\mathrm{H}_{2} \mathrm{O}_{2}$, has been shown to be present in leaves as a metabolite participating in a number of signalling events [19] and therefore it is available for UV-induced dissociation. Although leaves contain a variety of UV-absorbing compounds, especially in the upper epidermis, our experiments showed that the applied $308 \mathrm{~nm}$ UV-B reached chloroplasts localized in the inner mesophyll tissue and was capable of affecting leaf photochemistry and this effect was restricted to the UVB treated area (Supl. Fig.2.). $308 \mathrm{~nm}$ UV from the laser was mostly absorbed in the leaves, and approximately $0.01 \%$ of its original intensity penetrated the leaf tissue and was detectable at the other side of the leaf blade. Nevertheless, due to the complex structure of leaves, allowing both attenuation and focusing of incoming radiation [41], it is not possible to estimate the percentage of UV photons actually reaching photosynthetic tissues, and thus local ${ }^{\circ} \mathrm{OH}$ yields. Using fibre optics, Ålenius et al. [42] have shown that relatively large amounts of UV-B penetrated paradermal sections of Brassica napus.

Leaf photochemistry studies were carried out using Arabidopsis leaves, due to the availability of antioxidant mutants in this species. $308 \mathrm{~nm}$ laser irradiation was applied for $1 \mathrm{~min}$, and responses of wild type (Col-0) and $p d x 1.3-1$ mutant leaves were compared. Vitamin B6 (pyridoxine) is a strong - $\mathrm{OH}$ antioxidant [43] and wild type Arabidopsis leaves exposed to supplementary UV-B have been shown to accumulate it to a larger extent than the $p d x 1.3-1$ mutant [35]. In addition to less active ${ }^{\circ} \mathrm{OH}$ neutralization, a higher UV photo-production of this ROS is also likely since $p d x 1.3-1$ leaves UV-B exposed at $308 \mathrm{~nm}$ contained more $\mathrm{H}_{2} \mathrm{O}_{2}$ than Col-0, as shown in Fig. 2A using DAB staining.

Since its subcellular localization production is unknown, we can only speculate on the source of the $\mathrm{H}_{2} \mathrm{O}_{2}$ induced by $308 \mathrm{~nm} \mathrm{UV}$. However, since it was not observed in untreated leaves, it cannot be a wounding effect caused by cutting the leaves. In experiments using a combination of UV and visible light, it is usually assumed that the effect of UV-B includes damage to Rubisco [44,45], and thus ROS production in the Mehler-Asada pathway is increased to levels exceeding the neutralizing capacity of antioxidants [16]. Considering an analogous model to explain our data assumes that in addition to damaging the photosynthetic electron transport, UV-B could also be capable of driving it. Longer wavelength UV-A was shown to be utilized in algae [46] but there is no data available on UV$\mathrm{B}$ in this respect, although chlorophylls also absorb radiation in the UV-B region. Another possibility is to consider direct photochemical events, such as UV photodamage of the PS II electron acceptor $\mathrm{Q}_{\mathrm{A}}$ 
[47] or of the manganese-containing oxygen evolving complex of PS II [6]. Although not discussed in the context of UV-inducible damage, dysfunctional PS II complexes were suggested to produce $\mathrm{H}_{2} \mathrm{O}_{2}$ instead of oxygen from water [48,49]. Such a reaction could be a source of $\mathrm{H}_{2} \mathrm{O}_{2}$ in our experiment, although this mechanism would assume the UV-B-driven PS II electron transport discussed above. In addition, $\mathrm{H}_{2} \mathrm{O}_{2}$ sources other than chloroplasts may include the cell wall, in which UV-B was recently shown to lead to superoxide production [50].

The $1 \mathrm{~min} 308 \mathrm{~nm}$ treatments resulted in 20-40\% loss in the maximum PS II photochemical quantum yield $\left(\mathrm{F}_{\mathrm{v}} / \mathrm{F}_{\mathrm{m}}\right)$. Leaves of the the $p d x 1.3-1$ mutant appeared to suffer more UV-B induced less than those of Col-0 wild type but this difference was not statistically significant in the present data set (Fig.2B). Noting that direct, PS II level differences would also worth exploring in additional experiments we focussed on data obtained with light acclimated leaves. Although UV from the $308 \mathrm{~nm}$ laser $\mathrm{UV}$ radiation $\left(10.8 \mathrm{~W} \mathrm{~m}^{-2} \mathrm{~nm}^{-1}\right)$ was much stronger than the $308 \mathrm{~nm}$ spectral irradiance component of sunlight $\left(0.11 \mathrm{~W} \mathrm{~m}^{-2} \mathrm{~nm}^{-1}\right)$ (calculated [51] for $27^{\circ}$ zenith angle, cloud-free conditions, 300 Dobson units.), the effective PS II quantum yield of illuminated leaves measured using $280 \mu \mathrm{mol} \mathrm{m}^{-2} \mathrm{~s}^{-1}$ actinic PAR light was not significantly affected in Col-0. On the other hand, it was inhibited by approximately 50\% in pdx1.3-1 leaves (Fig. 2C). The fraction of PAR that is not converted by PS II, calculated as 1-Y(II), constitutes the total quantum yield of all dissipative processes. This is divided into two distinct components: (i) the energy being dissipated as heat via regulated photo-protective mechanisms (Y(NPQ)), or (ii) passive dissipation through other processes (Y(NO)) [39]. While UV-B treatment decreased Y(NPQ) equally in pdx1.3-1 and Col-0 leaves (Fig. 2D), Y(NO) increased to a larger extent in the $p d x 1.3-1$ mutant than in Col-0 (Fig. 2E). In general, high values of $\mathrm{Y}(\mathrm{NO})$ and low values of Y(NPQ) reflect suboptimal capacity of photo-protective reactions, potentially leading to photodamage by PAR [39] mediated by ROS [16,52]. Such a condition was caused by the $308 \mathrm{~nm}$ UV-B treatment and the fact that it was more severe in $p d x 1.3-1$ leaves than in Col-0 indicates that it was at least partly caused by ROS. The results above show that the effect of $308 \mathrm{~nm}$ UV-B irradiation of leaves is multiple: some UV-B photons increase $\mathrm{H}_{2} \mathrm{O}_{2}$ production and others split $\mathrm{H}_{2} \mathrm{O}_{2}$ into ${ }^{\circ} \mathrm{OH}$. In addition, these ROS are capable of lowering the ability of PS II to utilize PAR. After 1 min UV-B exposure this effect only manifested in the $p d x 1.3-1$ mutant that has a lower pyridoxine biosynthetic capacity (Fig.2) but UV-B also affected wild type leaves when it was applied for longer times (data not shown).

The UV-B-induced photo-conversion of $\mathrm{H}_{2} \mathrm{O}_{2}$ into ${ }^{\circ} \mathrm{OH}$ may also occur under field conditions, although it is expected to yield lower amounts of ${ }^{\circ} \mathrm{OH}$. Such low levels of ROS are expected to be able to be neutralized by the intracellular antioxidants by the plants. However, during other stress conditions, that themselves may induce either increased cellular $\mathrm{H}_{2} \mathrm{O}_{2}$ concentrations or less efficient function of antioxidants, when combined with UV-B, higher production or lower scavenging rates of - $\mathrm{OH}$ may in turn lead to higher actual concentrations of this ROS and can thus contribute to oxidative 
stress. Such an effect would explain why ambient solar UV-B only becomes a stress factor when combined with other unfavourable environmental factors such as high temperature or drought [4].

\section{Acknowledgements}

We thank Dr. Rudolf Tóth-Boconádi for his help with the $308 \mathrm{~nm}$ laser experiments at BRC Szeged. Cooperation between participating laboratories was aided by the COST Action FA0906 'UV4growth'. $\mathrm{GyCz}$ and ÉH are supported by grant No. OTKA NN-85349 of the Hungarian Scientific Grant Agency. ÅS is supported by grants from the Carl Trygger Foundation, the Knowledge Foundation, and Örebro University's Faculty for Business, Science and Technology. 


\section{References}

[1] Andrady, A.L., Aucamp, P.J., Austin, A.T., Bais, A.F., Ballaré, C.L., Björn, L.O., Bornman, J.F., Caldwell, M., Cullen, A.P., Erickson, D.J., de Gruijl, F.R., Häder, D.P., He, W., Ilyas, M., Longstreth, J., Lucas, R., McKenzie, R.L., Madronich, S., Norval, M., Paul, N.D., Redhwi, H.H., Robinson, S., Shao, M., Solomon, K.R., Sulzberger, B., Takizawa, Y., Tang, X., Torikai, A., van der Leun, J.C., Williamson, C.E., Wilson, S.R., Worrest, R.C., and Zepp, R.G. (2012) Environmental effects of ozone depletion and its interactions with climate change: progress report, 2011. United Nations Environment Programme, Environmental Effects Assessment Panel. Photochem. Photobiol. Sci. 11, 13-27

[2] Rozema, J., Van de Staaij, J., Björn, L.O., and Caldwell, M. (1997) UV-B as an environmental factor in plant life: stress and regulation. Trends Ecol. Evol. 12, 22-28

[3] Ballaré, C. L., Caldwell, M. M., Flint, S. D., and Robinson, S. A. (2011) Effects of solar ultraviolet radiation on terrestrial ecosystems. Patterns, mechanisms, and interactions with climate change. Photochem. Photobiol. Sci. 10, 226-241

[4] Hideg, É., Jansen, M. A. K., and Strid, ̊̊. (2013) UV-B exposure, ROS and stress: inseparable companions or loosely linked associates? Trends Plant Sci. 18, 107-115

[5] Jansen, M. A. K., Gaba, V., and Greenberg, B. M. (1998) Higher plants and UV-B radiation: balancing damage, repair and acclimation. Trends Plant Sci. 3, 131-135

[6] Vass, I., Szilárd, A., and Cosmin, S. (2005) in Handbook of Photosynthesis- $2^{\text {nd }}$ ed.: Adverse effects of $U V-B$ light on the structure and function of the photosynthetic apparatus, eds Pessarakli, M. (CRC press, New York), pp 827-845

[7] Hideg, É. and Vass, I. (1996) UV-B induced free radical production in plant leaves and isolated thylakoid membranes. Plant Sci. 115, 251-260

[8] Barta, Cs., Kálai, T., Hideg, K., Vass, I., and Hideg, É. (2004) Differences in the ROS generating efficacy of various ultraviolet wavelengths in detached spinach leaves. Funct. Plant Biol. 31, 23-28

[9] Šnyrychová, I., and Hideg, É. (2007) The first application of terephthalate fluorescence for highly selective detection of hydroxyl radicals in thylakoid membranes. Funct.l Plant Biol. 34, 1105-1111

[10] Lidon, F.J.C., Teixeira, M., and Ramalho, J. C.(2012) Decay of the chloroplast pool of ascorbate switches on the oxidative burst in UV-B-irradiated rice. J. Agron. Crop Sci. 198, 130-144

[11] Hideg, É., Nagy, T., Oberschall, A., Dudits, D., and Vass, I. (2003) Detoxification function of aldose/aldehyde reductase during drought and UV-B (280-320 nm) stresses. Plant Cell Environ. 26, 513-522

[12] Majer, P., and Hideg, É. (2012) Developmental stage is an important factor that determines the antioxidant responses of young and old grapevine leaves under UV irradiation in a greenhouse. Plant Physiol. Biochem. 50, 15-23

[13] Neill, S. J., Desikan, R., Clarke, A., Hurst, R. D., and Hancock, J. T. (2002) Hydrogen peroxide and nitric oxide as signalling molecules in plants. J. Exp. Bot. 53, 1237-1247

[14] Bienert, G. P., Møller, A. L. B., Kristiansen, K. A., Schulz, A., Møller, I. M., Schjoerring, J. K., and Jahn, T. P. (2007) Specific aquaporins facilitate the diffusion of hydrogen peroxide across membranes. J. Biol. Chem. 282, 1183-1192

[15] Møller, I. M., Jensen, P. E., and Hansson, A. (2007) Oxidative modifications to cellular components in plants. Annu. Rev. Plant Biol. 58, 459-481

[16] Asada, K. (2006) Production and scavenging of reactive oxygen species in chloroplasts and their functions. Plant Physiol.141, 391-396

[17] Ananyev, G, Renger, G., Wacker, U., and Klimov, V. (1994) The photoproduction of superoxide radicals and the superoxide dismutase activity of photosystem II. The possible involvement of cytochrome b559. Photosynth. Res. 41, 327-338

[18] Foyer, C. H, and Noctor, G. (2003) Redox sensing and signalling associated with reactive oxygen in chloroplasts, peroxisomes and mitochondria. Physiol. Plant. 119, 355-364

[19] Cheeseman, J. M. (2006) Hydrogen peroxide concentrations in leaves under natural conditions. J. Exp. Bot. 57, 2435-2444 
[20] Van Breusegem, F., Bailey-Serres, J., and Mittler, R. (2008) Unraveling the tapestry of networks involving reactive oxygen species in plants. Plant Physiol. 147, 978-984

[21] Sander, S. P., Friedl, R. R., Golden, D. M., Kurylo, M. J., Huie, R. E., Orkin, V. L., Moortgat, G. K., Ravishankara, A. R., Kolb, C. E., Molina, M. J. and Finlayson-Pitts, B.J. (2003) Chemical Kinetics and Photochemical Data for Use in Atmospheric Studies, Evaluation No. 14, JPL Publications 02-25. http://jpldataeval.jpl.nasa.gov/pdf/JPL_02-25_rev02.pdf

[22] Thiebault, J., Aluculesei, A., and Fittschen, C. (2007) Formation of $\mathrm{HO}_{2}$ radicals from the photodissociation of $\mathrm{H}_{2} \mathrm{O}_{2}$ at 248nm. J. Chem. Phys. 126, 186101

[23] Finlayson-Pitts, B. J., and Pitts, J. N., Jr. (2000) Chemistry of the Upper and Lower Atmosphere, Academic Press, San Diego

[24] Kuwata, K., Kotake, Y., Inada, K., and Ono, M. (1972) Electron spin resonance study of the far-ultraviolet photolysis of some inorganic and organic compounds. J. Phys. Chem. 76, 2061-2069

[25] Harbour, J. R., Chow, V., and Bolton, J. R. (1974) An Electron Spin Resonance Study of the Spin Adducts of $\mathrm{OH}$ and $\mathrm{HO}_{2}$ Radicals with Nitrones in the Ultraviolet Photolysis of Aqueous Hydrogen Peroxide Solutions. Can. J. Chem. 52, 3549-3553

[26] Van der Zee, J., Krootjes, B. B., Chignell, C. F., Dubbelman, T. M., and Van Steveninck, J. (1993) Hydroxyl radical generation by a light-dependent Fenton reaction. Free Radic. Biol. Med. 14, 105-113

[27] Khriachtchev, L., Pettersson M., Tuominen S., and Räsänen, M. (1997) Photochemistry of Hydrogen Peroxide in Solid Argon. J. Chem. Phys. 107, 7252-7259

[28] Pehkonen, S., Marushkevich, K., Khriachtchev, L., Räsänen, M., Grigorenko, B. L., and Nemukhin, A. V. (2007) Photochemical Synthesis of $\mathrm{H}_{2} \mathrm{O}_{2}$ from the $\mathrm{H}_{2} \mathrm{O} \cdots \mathrm{O}\left({ }^{3} \mathrm{P}\right)$ van der Waals complex: experimental observations in solid krypton and theoretical Modeling. J. Phys. Chem. A 111, 11444-11449

[29] Perpète, E. A., Wathelet, V., Preat, J., Lambert, C., and Jacquemin, D. (2006) Toward a Theoretical Quantitative Estimation of the $\lambda_{\max }$ of Anthraquinones-Based Dyes. J. Chem. Theory Comput. 2, 434-440

[30] Jacquemin, D., Wathelet, V., Perpète, E. A., and Adamo, C. (2009) Extensive TD-DFT Benchmark: Singlet-Excited States of Organic Molecules. J. Chem. Theory Comput. 5, 24202435

[31] Ristilä, M., Matxain, J. M., Strid, Å., and Eriksson, L. A. (2006) pH-dependent electronic and spectroscopic propterties of pyridoxine (vitamin B6). J. Phys. Chem. B. 110, 16774-16780

[32] Musa, K. A. K., Matxain, J. M., and Eriksson, L. A. (2007) Mechansim of photoinduced decomposition of ketoprofen. J. Med. Chem. 50, 1735-1743

[33] Wu, M., Eriksson, L. A., and Strid, A. (2011) Computational evidence for the role of Arabidopsis thaliana UVR8 as UV-B photoreceptor, and identification of its chromophore amino acids. J. Chem. Inf. Model. 51, 1287-1295

[34] Frisch, M. J., Trucks, G. W., Schlegel, H. B., Scuseria, G. E., Robb, M. A., Cheeseman, J. R., Scalmani, G., Barone, V., Mennucci, B.; Petersson, G. A., Nakatsuji, H., Caricato, M., Li, X.; Hratchian, H. P., Izmaylov, A. F., Bloino, J., Zheng, G., Sonnenberg, J. L., Hada, M., Ehara, M., Toyota, K., Fukuda, R., Hasegawa, J., Ishida, M., Nakajima, T., Honda, Y., Kitao, O., Nakai, H., Vreven, T., Montgomery, J. A. J., Peralta, J. E., Ogligro, F., Bearpark, M., Heyd, J. J., Brothers, E., Kudin, K. N., Staroverov, V. N., Kobayashi, R., Normand, J., Raghavachari, K., Rendell, A., Burant, J. C., Iyengar, S. S., Tomasi, J., Cossi, M., Rega, N., Millam, J. M., Klene, M., Knox, J. E., Cross, J. B., Bakken, V., Adamo, C., Jaramillo, J., Gomperts, R., Stratmann, R. E., Yazyev, O., Austin, A. J., Cammi, R., Pomelli, C., Ochterski, J. W., Martin, R. L., Morokuma, K., Zakrzewski, V. G., Voth, G. A., Salvador, P., Dannenberg, J. J., Dapproch, S., Daniels, A. D., Farkas, O., Foresman, J. B., Ortiz, J. V., Cioslowski, J., and Fox, D. J. (2009) Gaussian 09, Version D.01, Gaussian, Inc., Wallingford, CT

[35] Ristilä, M., Strid, H., Eriksson, L. A., Strid, A., and Sävenstrand, H. (2011) The role of the pyridoxine (vitamin B6) biosynthesis enzyme PDX1 in ultraviolet-B radiation responses in plants. Plant Physiol. Biochem. 49, 284-292

[36] Śnyrychová, I., Ayaydin, F., and Hideg, É. (2009) Detecting hydrogen peroxide in leaves in vivo - a comparison of methods. Physiol. Plant. 135, 1-18 
[37] Thordal-Christensen, H., Zhang, Z., Wei, Y. D., and Collinge, D. B. (1997) Subcellular localization of $\mathrm{H}_{2} \mathrm{O}_{2}$ in plants. $\mathrm{H}_{2} \mathrm{O}_{2}$ accumulation in papillae and hypersensitive response during the barley-powdery mildew interaction. Plant J. 11, 1187-1194

[38] Schreiber, U. (2004) in Chlorophyll a fluorescence: a signature of photosynthesis: pulseamplitude-modulation (PAM) fluorometry and saturation pulse method: an overview, eds $\mathrm{Pa}-$ pageorgiou, G. C., and Govindjee (Kluwer Academic Publishers, Dordrecht, The Netherlands), pp 279-319

[39] Klughammer, C., and Schreiber, U. (2008) Saturation pulse method for assessment of energy conversion in PSI. PAM Appl. Notes 1, 11-14

[40] Chu, L., and Anastasio, C. (2005) Formation of hydroxyl radical from the photolysis of frozen hydrogen peroxide. J. Phys. Chem. A 109, 6264-6271

[41] Vogelmann, T. C., Bornman, J. F., and Yates, D. J. (1996) Focusing of light by leaf epidermal cells. Physiol. Plant. 98, 43-56

[42] Ålenius, C. M., Vogelmann, T. C., and Bornman, J. F. (1995) A three-dimensional representation of the relationship between penetration of u.v.-B radiation and u.v.-screening pigments in leaves of Brassica napus. New Phytol. 131, 297-302

[43] Matxain, J. M., Padro, D., Ristilä, M., Strid, A., and Eriksson, L.A. (2009) Evidence of high *OH radical quenching efficiency by vitamin B6. J. Phys. Chem. B 113, 9629-9632

[44] Strid, A., Chow, W. S., and Anderson, J. M. (1990) Effects of supplementary ultraviolet-B radiation on photosynthesis in Pisum sativum. BBA-Bioenergetics 1020, 260-268

[45] Jordan, B.R., He, J., Chow, W.S., and Anderson, J.M. (1992) Changes in mRNA levels and polypeptide subunits of ribulose 1,5-bisphosphate carboxylase in response to supplementary ultraviolet-B radiation. Plant, Cell \& Environ. 15, 91-98

[46] Xu, J., and Gao, K. (2010) Use of UV-A energy for photosynthesis in the red macroalga Gracilaria lemaneiformis. Photochem. Photobiol. 86, 580-585

[47] Melis, A., Nemson, J.A., and Harrison, M.A. (1992) Damage to functional components and partial degradation of Photosystem II reaction center proteins upon chloroplast exposure to ultraviolet-B radiation. Biochim. Biophys. Acta 1100, 312-320

[48] Fine, P. L., and Frasch, W. D. (1993) The oxygen-evolving complex requires chloride to prevent hydrogen peroxide formation. Biochemistry 31, 12204-12210

[49] Wydrzynski, T., Hillier, W., and Messinger, J. (1996) On the functional significance of substrate accessibility in the photosynthetic water oxidation mechanism. Physiol. Plant. 96, 342350

[50] Pristov, J. B., Jovanović, S. V., Mitrović, A., and Spasojević, I. (2013) UV-irradiation provokes generation of superoxide on cell wall polygalacturonic acid. Physiol. Plant. 148, 574581

[51] http://cprm.acd.ucar.edu/Models/TUV/Interactive_TUV/

[52] Apel, K., and Hirt, H. (2004) Reactive oxygen species: metabolism, oxidative stress, and signal transduction. Annu. Rev. Plant Biol. 55, 373-399 


\section{Figure legends}

\section{Figure 1.}

A, Fluorescence spectra of TPA and TPA $+\mathrm{H}_{2} \mathrm{O}_{2}$ pre-treated with various doses of $284 \mathrm{~nm}$ UV-B. Excitation wavelength $315 \mathrm{~nm}$. Note that untreated TPA (TPA) and TPA (TPA, $200 \mathrm{~mJ}$ ) spectra are overlapping. B, Action spectrum of $\mathrm{UV}$-inducible $\mathrm{H}_{2} \mathrm{O}_{2} \rightarrow^{\bullet} \mathrm{OH}$. Circles show data, error bars characterize the goodness of linear fits giving wavelength dependent ${ }^{\circ} \mathrm{OH}$ generating efficiencies (see Materials and Methods for details) and the solid line shows a fit with two Gaussian components (maxima at 296 and $284 \mathrm{~nm}$, dashed lines). C,D, UV absorption spectra of $\mathrm{H}_{2} \mathrm{O}_{2}$ and ${ }^{\circ} \mathrm{OH}$ radical obtained at the B3LYP/6-31+G(d,p) level. Theoretical absorption wavelengths are shown as dashed vertical lines and the theoretical UV spectra as solid lines.

\section{Figure 2.}

Responses of wild type (Col-0) and $p d x 1.3-1$ (pdx) mutant Arabidopsis leaves to 1 min $308 \mathrm{~nm}$ UV-B treatment. A, $\mathrm{H}_{2} \mathrm{O}_{2}$ reactive DAB staining of untreated and UV-B treated leaves. B,C,D,E, Chlorophyll fluorescence derived photosynthesis parameters of untreated and UV-B treated (hashed) wild type (white bars) and pdx (grey bars) leaves. Bar heights and error bars represent average values and standard deviations $(\mathrm{n}=3)$. Significantly $(\mathrm{p}<0.05)$ different values are marked with different letters.

\section{Supplementary Figure 1.}

A, Energy curves for stretching the $\mathrm{O}-\mathrm{O}$ bond in $\mathrm{H}_{2} \mathrm{O}_{2}$ in the ground state and the four lowest single excited states. B, Energy curves for stretching the $\mathrm{O}-\mathrm{H}$ bond in ${ }^{\circ} \mathrm{OH}$ radical in the ground state and the four lowest single excited states.

\section{Supplementary Figure 2.}

Colour coded image of maximum quantum yield of PS II photosynthesis $\left(\mathrm{F}_{\mathrm{v}} / \mathrm{F}_{\mathrm{m}}\right)$ in a tobacco leaf previously exposed to $6 \mathrm{~min} 308 \mathrm{~nm}$ UV-B at a $1 \mathrm{~cm}$ diameter circular spot. 
A

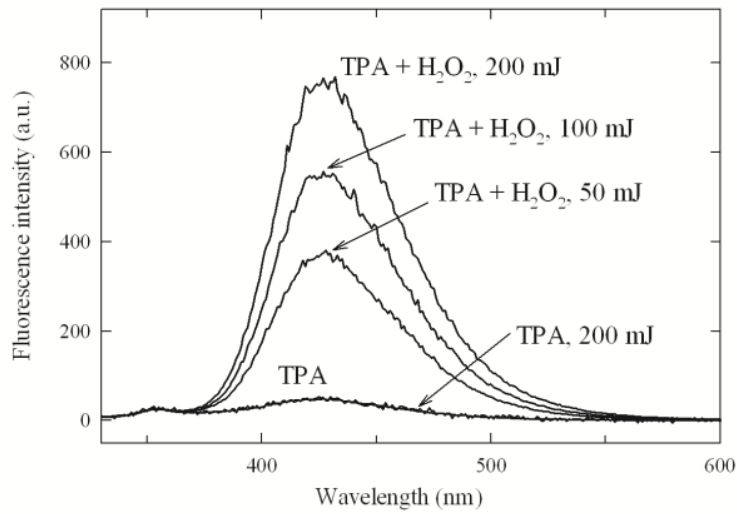

$\mathrm{C}$

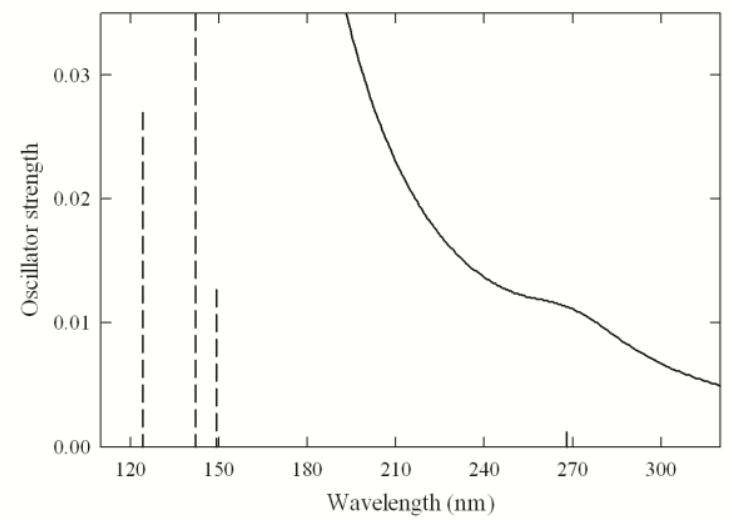

B

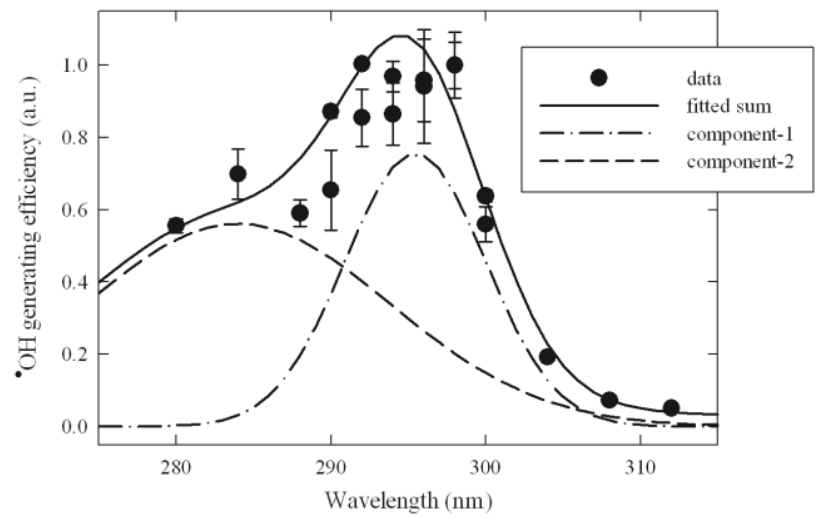

D

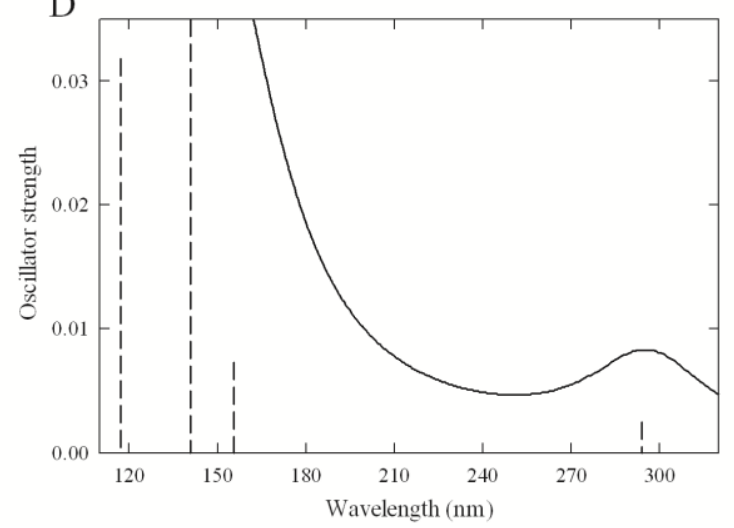

Figure 1 
A

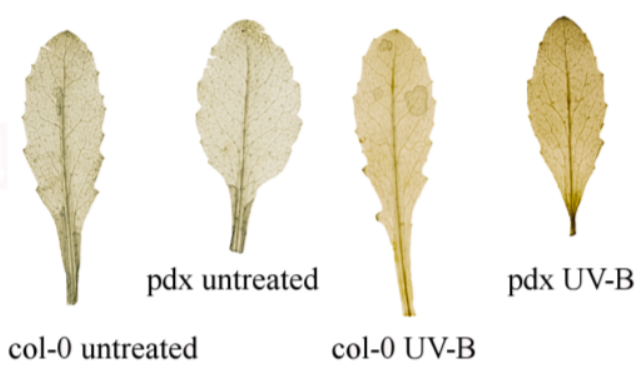

B

$\mathrm{C}$
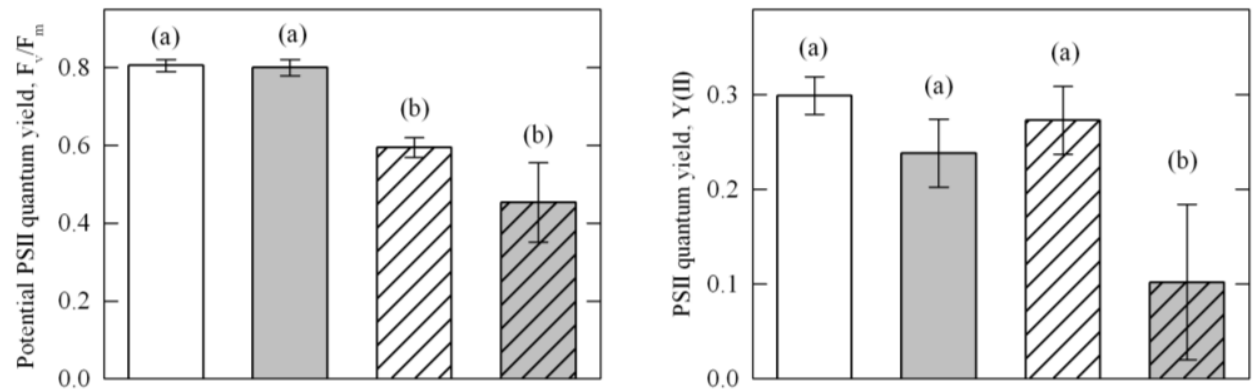

D

E
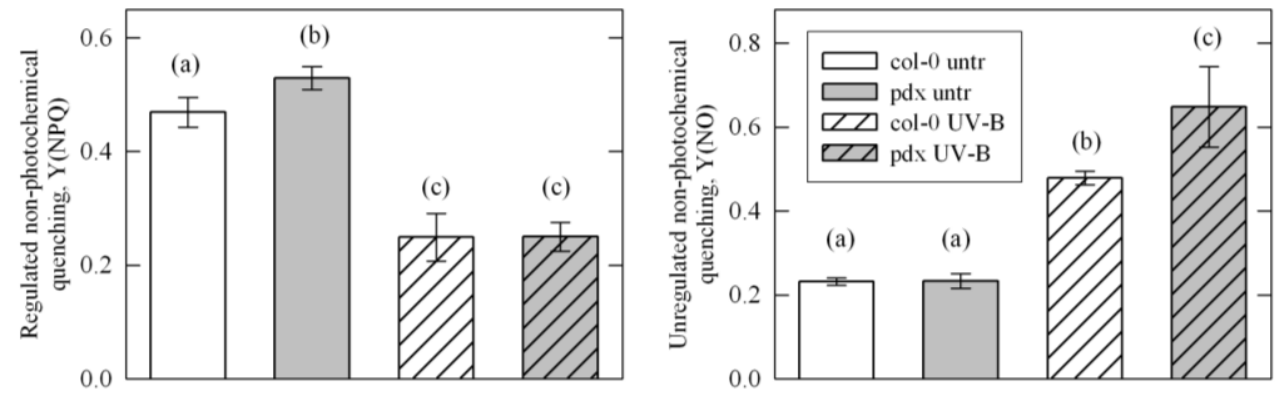

Figure 2 

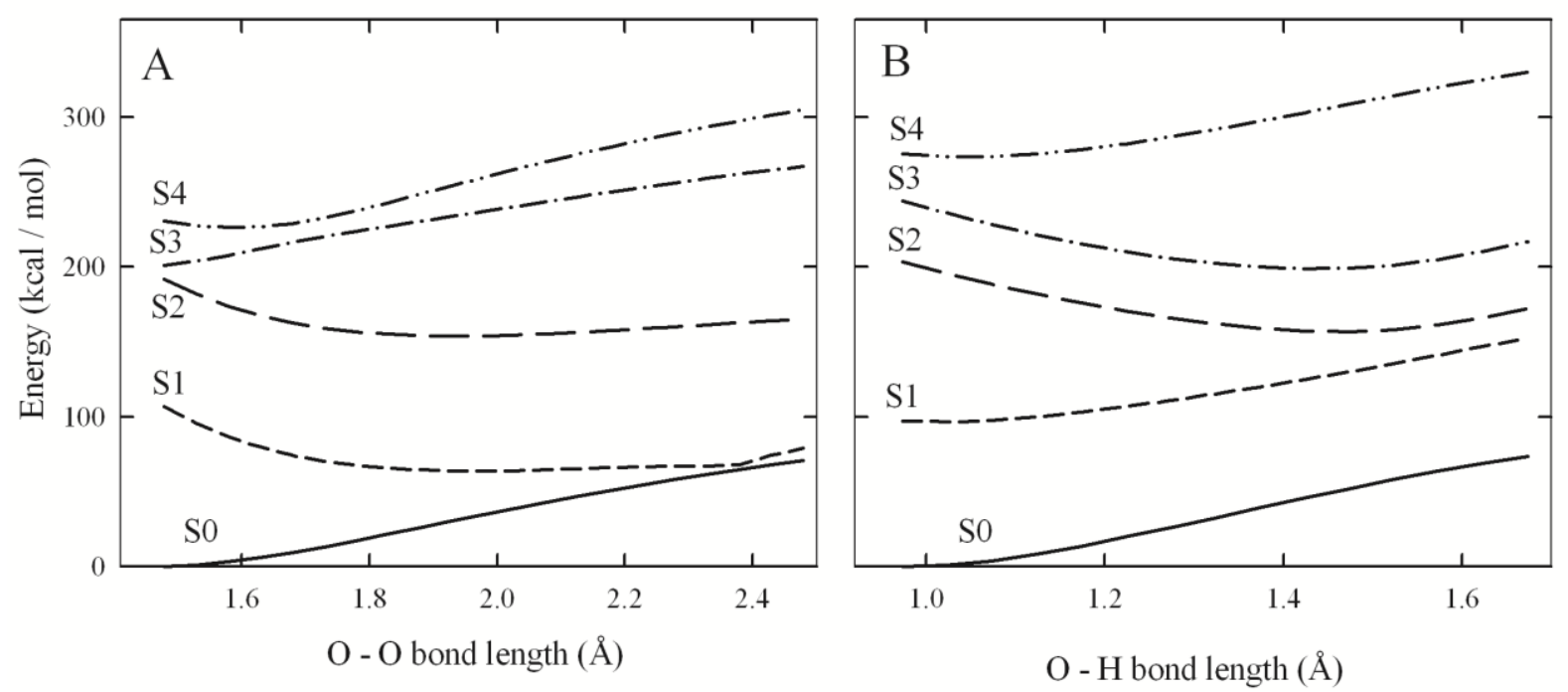

Supplementary Figure 1.

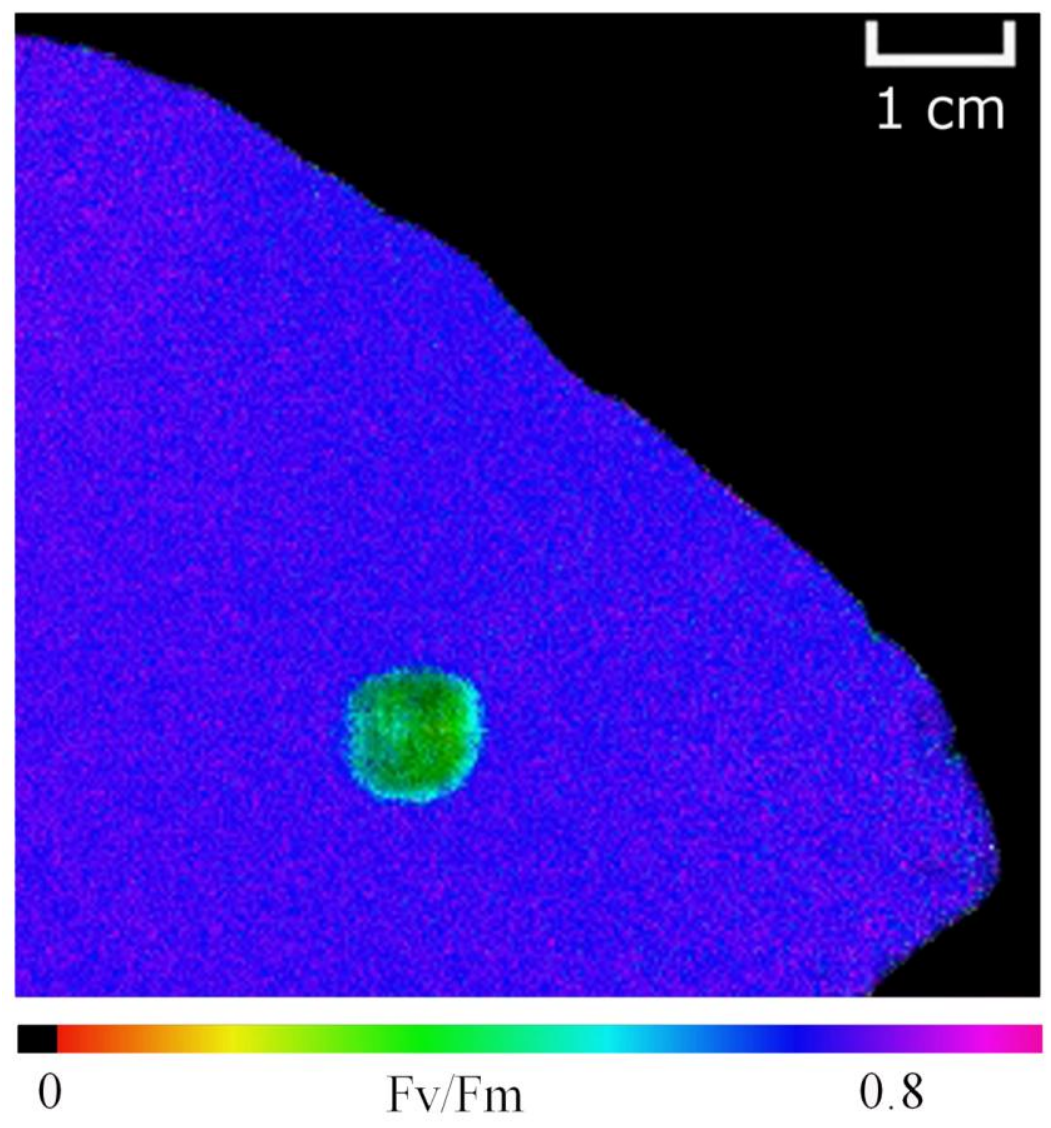

Supplementary Figure 2. 